\title{
Open Access to Resource Integration Research
}

\author{
Zhiyin Yang $^{\mathrm{a}}$ and Jiakun $\mathrm{Hu}^{\mathrm{b}}$ \\ Information and Technology College, Jilin Agricultural University, Jilin, China \\ a23133124@qq.com, b942357462@qq.com
}

\begin{abstract}
Keywords: OA Movement; Consolidation Pattern; Development Strategy
\end{abstract}
\begin{abstract}
This paper elaborates on the definition and type of open access resources. At the same time, the feasibility and practical significance of the open access resource integration are analyzed. This paper analyzes the integration pattern of OA resources from the perspective of social practice application. Points out the problems of resource integration and its development strategy.
\end{abstract}

\section{Introduction}

Open Access (Open Access, OA) movement originated in the late $1990 \mathrm{~s}$, it is in order to solve the problem of "crisis of academic journal", to build a truly serve the scientific research of academic communication system, in the international academia, publishing and information of professional large-scale emergence of media and books and sports. Its core idea is: free and barrier-free use of literature information. Free access to information resources, its biggest advantage is that it can make users more convenient and free to conduct academic and other research exchanges. With the development of network information technology, the traditional academic journals publishing model already can't satisfy people's needs, people use of document information way there has been a fundamental change, more and more used to access and use through the network literature, and open access just meet this demand, make personal research results in a short period of time, the maximum extent, to understand and spread by people, so as to realize the value of their own. Therefore, it is very important to study the information resources in an open and integrated way.

In the process of open access resources integration, follow the principle of open access resources integration, realize the goal of open access resources integration, collection, organization and retrieval of open access resources, utilization and management of the research and implementation has important theory significance [1].Readers can get the information they need with minimal cost, and the authors can improve their working ability and their work impact [2].

\section{Open Access to Resource Overview}

Definitions. Open Access (Open Access, OA) is most widely quoted definition of the Budapest Open Access initiative, whose description is: "Access to literature exists different policies and permissions, and the literature of the Open Access means that the user can through the public Internet free to read, download, copy, distribute, print, and retrieve the works, or to work full text links, for indexing and will work as the data is passed to the corresponding software, the use of any other for legal purpose [3]."Open access maintains the integrity of the literature at the time of access, which is the only restriction on its replication and delivery. Open access is a new and different from traditional academic communication barrier-free communication system, it is on the premise of respect the rights and interests of the author, using the Internet for free for the user to provide academic information and research results of the full service. And media forms to the survival of the Internet is open access, this is because the development of the Internet led to a decline in academic communication cost, is give priority to with the official publication of the traditional system of academic exchange, thus provides the open access of academic information may [4].

Types. The open access journal is a free online journal that aims to enable all users to access the full text of a journal article without limit. This kind of periodical generally adopts the author's paid publishing, free access to readers and unlimited usage mode. The copyright of the thesis is reserved by the author. 
Open access journals use copyright and other tools to ensure that the literature is available for public access.

OA warehousing is also known as OA knowledge base, including the discipline based storage and institutional storage.

Subject OA is an academic exchange in the field of physics, computer, astronomy and other natural sciences. It is a kind of academic exchange in the field of the topic in the form of pre-printed copy [3 5].

In addition to the above two types, open access resources include other resources such as personal websites, electronic books, blogs, academic BBS, file-sharing networks, etc.

The release of these resources is relatively free, with more casual and academic value

\section{Open Access to Resource Integration Feasibility and Practical Significance}

Open Access to Resource Integration Feasibility. Open access resources is arises at the historic moment with resource increasingly, online free, free to read, download, copy, spread the full text of resources is increasing, more and more organizations to participate in the open access resources integration of sports [6].Numerous journals and databases have been established, and OA Resources have increased. Therefore, it is important to integrate the information resources distributed on different servers and websites.

The condition of open access to resource integration is to diversify its development. Various types of OA resources content is complex, and the integration of OA resources it is in this complex resource types in the changing conditions, it is not only the urgent needs of the information users, and information processing personnel tasks and responsibilities [6].

Because of its spontaneity, the open access movement has been in a disordered state of management and utilization of OA resources, and has become an urgent problem in information management [6].Therefore, the main purpose of integrating OA resources is to strengthen the acquisition and utilization of OA resources to realize the orderly integration of OA resources.

To improve the purchasing ability of information organization resources, we can have the impetus to integrate OA resources. In recent years, the rising prices of periodicals and books have led to a decline in the resources purchasing power of various information institutions, and the literature guarantee rate has decreased year by year. So the integration of OA resources, to improve information institutions resource reserves, to improve the purchasing power of various information organization resources and construction ability, makes the limited funds into the construction of more resources, improve resource construction ability [6].

Open Access to Resource Integration. Open access resource of digital information resources, it is open and obtaining is carried out on the computer network, to get rid of the traditional paper publishing model, the model makes the literature and academic information more easily query and download to use, easy to scholars for academic learning and communication each other, avoid the traditional paper publishing model because of its inherent defects of delay and so on many insurmountable problem, make academic exchanges become more open, and then make the academic progress and development.

The open access movement breaks the price restriction of traditional paper publishing, which makes the circulation of literature more freely. The integration of open access resources, the user access to literature has greatly expanded, social industries, departments can be quick and easy free access to the required resources, in addition to the academic, scientific research and education aspects of resources, more for production technology, entertainment and so on various aspects of resource collection, analysis, download, use and spread. With the basic knowledge and information, the society can develop comprehensively.

The integration of open access resources is not only the need to perfect the integration of knowledge resources, but also to deepen the theoretical research of the knowledge organization. Will open access resources, as a relatively independent type of knowledge resources, a comprehensive understanding of open access resources connotation and characteristics, collection, organization and retrieval of open access resources, utilization and management of the research and 
implementation has important theoretical significance, to promote the resources integration in the field of knowledge organization system has important theoretical significance and practical significance.

The integration of open access resources is not only the need for the integration of knowledge resources, but also the need to guide the practice of resource integration. Comprehensive knowledge systematically research of open access resources integration, to master the essential characteristics of open access resources integration activities and objective laws, to solve in the development of open access resources integration practice new problems appear constantly, guide and promote the development of integrated practice quickly and orderly, has important practical significance.

\section{Open Access to Resource Integration Patterns}

Cross-industry Retrieval Integration Model by Different Structure. The integration of open access resources is for users to use, to provide users of different industries with the information resource retrieval system platform. Each industry is interconnected, and the inter-industry links form a network of normal social stability, and the open access resources between industries need to be clearly organized. The parts of the industry and other industries are connected with each other, and they are analyzed, collected, classified and screened according to their nature so as to facilitate user's quick inquiry and utilization.

Within the same system, each department has its own resources, more connected parts, forming a complete collective. For example, the government's land departments and urban construction departments, respectively, manage their respective affairs and archives resources, while urban construction involves land, and land will encounter urban construction problems. Classifying and integrating them can solve confusing and confusing problems and avoid unnecessary misunderstandings. Such an integration model involves a wide range of social aspects. The classification work is more complex, and the content is more comprehensive and specific, so that the information resources can be utilized by the users.

The Integration of Various Aspects of Society According to Different Content. The data resources in the database are different from each other. In many ways, many retrieval platforms lack the integration of open access resources for mass users, and more emphasis on academic research. For open access resources, should not be limited to the integration of professional academic knowledge, more should be involved in all aspects of social production and life, such as production technology, entertainment and academic research, etc., carry on the classification and sorting, expand the area of resources, form a rich information resources available. To the different aspects of the content to be archived, division, more detailed classification, the user can access at any time, not influenced by the resources required content factors, enhance people's understanding and use of open access resources, made of open access resources utilization by [8 10].

\section{Open Access to Resource Integration Problems and Solutions}

Problems. Some OA resource integration platforms lack the semantic correlation results between topics and keywords, and there is no retrieval result of the synonyms or synonyms. In addition, the range of OA resources included in the various integration platforms also has a great limitation.

The academic and technical aspects involved are not comprehensive enough to carry out comprehensive retrieval, resulting in a great restriction on .

Some of the larger open access resource integration platforms in China have failed to make free and free sharing of information resources. Most of them require a fee to get access to academic, technical, and other resources, causing user inconvenience. Domestic institutions, universities and other unified purchase of resource platforms for internal personnel to search and use, make open access to resources have limitations, cannot make all people use .Even if there are some resources published online, the content is limited, and it is often only part of the content or introduction of resources. 
With the increasing resources of open access to the Internet, new open resources are added to the network every day to become a necessary resource for scientific research. In contrast, many domestic open access resources platform for the construction of the content of the repeatability is bigger, the same, the open access resources lack of innovative, great waste of the space system.

Strategy. Retrieval result lack of correlation between this kind of situation because retrieval technology advanced enough in our country, therefore should focus on independent development of new technology, a comprehensive collection of various aspects of various disciplines resources, to make up for the lack of available resources. Resources integration is to establish a comprehensive, with the semantic association, expand the intelligent network environment of human knowledge, to solve the problem of semantic association of cross-language, etc. to solve the problems of the existing OA resources search scope is narrow, is able to enhance the precision of the literature information and recall ratio, increase the integration of OA resources to a new and higher level.

In order to truly realize the integration of open access resources, it is necessary to construct an integrated platform with completely open information resources.

The platform will not only the same type and its related subjects together a collection of information resources integration, the realization of the main free sharing of information resources, can make a free sharing information resources, access to the information they need to make their resources. To achieve this, not only need technical support, but also economic guarantee and other aspects of support.

Should be real-time tracking the change of open source, to integrate processing in time, maintain the stability of integrate system of open access resources and novel, realize the user to open the effective utilization of resources, the greatest degree of saving the space of system, avoid the waste of resources.

Also, pay attention to system maintenance and update. The various retrieval and service systems established through open access to resource integration are the most convenient way for users to obtain open resources. Timely modification, update and maintenance of open access data can ensure the normal use of the open access resource system.

\section{Conclusion}

As a new publishing mode, open access has changed the way of academic communication, which is the goal of scientific information accessibility in the network environment. It makes the academic exchanges with convenient accessibility, prompt the academic achievement can be faster and more widely, the spread of freer, and often get reference, so as to better solve the academic journal of crisis communication. At present, China's open access is still relatively low in users, and most users have never heard of open access, and fewer users have used open access resources. Therefore, it is very important to develop and open access to literature network platform and establish open access journals and open access knowledge navigation library. So, the development of open access literature network platform, set up open access journals and for the discovery, acquisition, integration, use of open access resources, to provide users with convenient access to methods and ways, promote the development and utilization of open access resources and integrate, expansion of the space for the service of the user, all has the very vital significance. Open access to knowledge navigation libraries becomes particularly important.

\section{References}

[1] X.H. Lu, L.X. Zhang: Information Science, (2011) No.2, p.253.

[2] S. Arunachalam: Library and Information Service, Vol. 50 (2006) No.1, p.34.

[3] X.Q. Ji, P. Liu, H.H. Zhang: Science and Technology Archives. (2010) No.3, P.15.

[4] S.Y. Guo: Research on an Institutional Repository based on Open Access (MS. Northeast Normal University, China 2006), p.5.

[5] J. Zhao: Library Science, (2006) No.4 p.64. 
[6] L.X. Zhang: Open Access to Resource Knowledge Integration Research (MS. Northeast Normal University, China 2010), p.3.

[7] Y.X. Zhang: Study on the Integration Mode of the Open Access Resources of University Libraries (MS. Shandong University, China 2012), P.12

[8] Y.F. Fan, J.H. Gao: Intelligence Theory and Practice, (2009) No. 1, P.66

[9] L.P. Zhang, Y. Wang and Y. Chen: Library Science, (2007) No. 9 P.20.

[10] F. Shen: Modern Intelligence, (2007) No. 109 P.114. 